\title{
Uma reflexão sobre a teoria da ação comunicativa de Habermas e a teoria dos gêneros textuais de Marcuschi nos espaços educativos
}

\author{
Francine Baranoski Pereira ${ }^{1}$
}

Ana Lúcia Pereira ${ }^{2}$

\section{Resumo}

Este artigo apresenta considerações sobre a importância da linguagem como expressão do pensamento nos mundos subjetivo e social. O objetivo deste estudo é propor reflexões sobre a Teoria da Ação Comunicativa de Habermas (1997), a linguagem nos espaços educativos por meio dos gêneros textuais propostos pelos Diretrizes Curriculares do Estado do Paraná (2008) com base na Teoria dos gêneros textuais de Marcuschi (2008). Esta discussão tem caráter multidisciplinar e atinge principalmente a área da Educação, no intento de provocar reflexões em professores e estudiosos que se interessem pela linguagem e seu produto, o texto. A abordagem metodológica, do ponto de vista dos procedimentos técnicos, caracteriza-se como argumentativa de caráter bibliográfico. As teorias aqui apresentadas, complementam-se e tornam-se leituras indispensáveis para o pensar contemporâneo da educação, bem como para o ensino dos gêneros textuais.

\section{Palavras-chave: Linguagem. Ação Comunicativa. Gêneros Textuais. Educação. Ensino}

\section{Resumen}

Este artículo presenta consideraciones sobre la importancia del lenguaje como expresión del pensamiento en los mundos subjetivo y social. El objetivo de este estudio es proponer reflexiones sobre la Teoría de la Acción Comunicativa de Habermas (1997), el lenguaje en los espacios educativos a través de los géneros textuales propuestos por los Documentos Curriculares del Estado de Paraná (2008) con base en la Teoría de los géneros textuales de Marcuschi. (2008). Esta discusión tiene un carácter multidisciplinar y afecta principalmente al área de Educación, en un intento de provocar reflexiones en docentes y académicos interesados en el lenguaje y su producto, el texto. El enfoque metodológico, desde el punto de vista de los procedimientos técnicos, es argumentativo de carácter bibliográfico. Las teorías aquí presentadas se complementan y se convierten en lecturas imprescindibles para el pensamiento contemporáneo en educación, así como para la enseñanza de géneros textuales.

\footnotetext{
${ }^{1}$ Mestre em Ensino de Ciência e Tecnologia, Universidade Técnológica Federal do Paraná, Brasil e Doutoranda em Educação, Universidade Estadual de Ponta Grossa, Ponta Grossa, Brasil. francine.baranoski@ hotmail.com

${ }^{2}$ Doutora em Ensino de Ciências e Educação Matemática, professora do Departamento de Matemática e Estatística da Universidade Estadual de Ponta Grossa, Ponta Grossa, Brasil. ana.lucia.pereira.173@gmail.com

Recibido 05/03/2021. Aceptado 12/05/2021
} 
Palabras clave: Lenguaje. Acción comunicativa. Géneros textuales. Educación. Enseñanza

\title{
A reflection on Habermas's theory of communicative action and Marcuschi's theory of textual genres in educational spaces
}

\begin{abstract}
This article presents considerations about the importance of language as an expression of thought in the subjective and social worlds. The objective of this study is to propose reflections of Habermas' Theory of Communicative Action (1997) and language in educational spaces through the textual genres proposed by the Curricular Guidelines of the State of Paraná (2008) based on Marcuschi's Theory of textual genres (2008). This discussion has a multidisciplinary character and affects mainly the area of Education, in an attempt to provoke reflections in teachers and scholars who are interested in language and its product, the text. The methodological approach, from the point of view of technical procedures, is characterized as argumentative of bibliographic character. The theories presented here complement each other and become essential readings for contemporary thinking in education, as well as for the teaching of textual genres.
\end{abstract}

Keywords: Language. Communicative Action. Textual genres. Education. Teaching

\section{Introdução}

A linguagem é um sistema de signos que possibilita a comunicação entre os seres humanos. Através da linguagem nos apresentamos ao mundo e o mundo se apresenta a nós. Nos permite organização de pensamento, nomeação de seres, coisas, interação com outros sujeitos, entendimento do mundo.

Por meio da linguagem há compartilhamento de ideias, conceitos, informações e aprendizado. Permite um processo mental que subsidia a modelagem do mundo, isto é, a linguagem dá vida ao pensamento.

A linguagem é um fator social, expressão de pensamento, própria do ser humano, enquanto a língua, é o uso de um código que permite a ação social interativa entre os indivíduos. Assim, para Habermas (1997) a relação com outros indivíduos, intersubjetiva, se dá quando estes falam e atuam buscando compreensão entre si sobre algo, através da linguagem em seu mundo social.

Cabe salientar, que o processo de formação de conceitos está ligado às relações entre pensamento e linguagem, mundo subjetivo, e o domínio destes conceitos, mediado pela cultura, mundo social. É papel da escola mediar estes processos, para que o estudante os transforme em conhecimento. Esta transformação, o aprendizado, ocorre através da leitura/escrita dos gêneros textuais, que para Marcuschi (2008) são textos materializados em situações comunicativas que circulam socialmente.

Considera-se que os gêneros textuais compõem o discurso e devem levar uma mensagem oral ou escrita com significação ao interlocutor. Para Marcuschi (2008) em cada situação comunicativa, os gêneros textuais são escolhidos pelos interlocutores para transmitir uma mensagem.

Deste modo, este artigo objetiva ressaltar o papel social da linguagem para comunicação e emancipação dos indivíduos com base na Teoria da Ação Comunicativa de Habermas (1997) e enfatizar o papel da linguagem nos espaços educativos como meio de expressão e de comunicação interativa que favorece o pensamento crítico, reflexivo e o aprendizado, por meio dos gêneros textuais com base na teoria de Marcuschi (2008). Para fins de exemplificação, 
aborda-se brevemente a proposta das Diretrizes Curriculares do Estado do Paraná-Brasil (2008) de trabalho com os gêneros textuais.

\section{A Teoria da ação comunicativa de Jürgen Habermas}

Habermas em sua Teoria da ação comunicativa propõe o modelo da comunicação no lugar do modelo da consciência. Este está fundamentado na busca do entendimento do mundo pelo indivíduo pensante em uma relação subordinada entre objeto e indivíduo. Habermas (1989) propõe uma quebra de paradigma com a teoria da ação comunicativa a qual espera possibilitar uma volta à crítica da razão instrumental e sugere uma retomada a atividades que se voltem a uma teoria crítica da sociedade.

Habermas em sua Teoria da ação comunicativa (1997) aborda principalmente as condições dadas por situações de fala nas quais os indivíduos interagem, utilizando-se do discurso argumentativo, chegando ao entendimento consensual. O referido autor propõe que os indivíduos interajam no seu lugar de fala com argumentos que levem à consonância entre os pares. Trata também do conceito de racionalidade com base no diálogo que liberta os indivíduos e os emancipa. Habermas esclarece neste conceito que os indivíduos são capazes de refletirem criticamente sobre os acontecimentos sociais. Sugere ações democráticas e coletivas que formem o pensamento comunicativo, reflexivo e crítico, fundamentais para a educação formal.

Em sua Teoria, parte do princípio de que os indivíduos são capazes de ação, e usam a linguagem para a comunicação com outros indivíduos, a fim de chegar a um entendimento, sendo a linguagem interativa e libertadora:

Chamo ação comunicativa àquela forma de interação social em que os planos de ação dos diversos atores ficam coordenados pelo intercâmbio de atos comunicativos, fazendo, para isso, uma utilização da linguagem (ou das correspondentes manifestações extraverbais) orientada ao entendimento. À medida em que a comunicação serve ao entendimento (e não só ao exercício das influências recíprocas) pode adotar para as interações o papel de um mecanismo de coordenação da ação e com isso fazer possível a ação comunicativa. (Habermas, 1997, p.418).

Postula que o entendimento é possível se a comunicação não é instrumental, a relação de interação entre os indivíduos ocorre pela ação da linguagem em um contexto de explanação de ideias e intenções mediada pela comunicação, reflexão e posterior entendimento entre os pares:

Há uma indefinida quantidade de signos ou símbolos que podem servir para o propósito do que chamamos 'linguagem'. Estamos lendo o significado da conduta das outras pessoas quando, quiçá, estas não têm consciência disso. Há algo que nos revela qual é o propósito - um olhar, a atitude do corpo que leva à reação. A comunicação estabelecida deste modo entre os indivíduos pode ser perfeita (Habermas, 1989, p. 370).

A ação comunicativa ocorre com diferentes indivíduos que interagem por meio de atos comunicativos através da linguagem orientados por sua subjetividade a fim de compreender 
determinado fato e universalizar seus interesses em uma explanação e posterior discussão. Neste ponto, os indivíduos devem estar abertos à pluralidade e criticidade de ideias. Do contrário, após compartilhar suas ideias plurais, se houver discordância e divergências, os indivíduos não chegam a um consenso. O desejável é que a partir dos atos comunicativos mediados pela linguagem, haja uma discussão reflexiva e crítica das ideias e entendimento dos posicionamentos. Assim, a racionalidade acontece e se torna um meio de emancipação dos seres em suas ações e entendimento do mundo.

A subjetividade dos indivíduos é formada pelo processo de interação nas comunicações mediadas pela linguagem e não ocorre em um ato reflexivo e solitário. A interação social moldou o homem em suas formas de sentir, pensar e agir.

$\mathrm{Na}$ concepção de Habermas, a linguagem é entendida como toda e qualquer maneira de comunicação modificadora do comportamento, pois é vista como ponto de conexão e interação entre os indivíduos como meio de assegurar argumentações para se chegar a decisões consensuais.

Assim, em sua teoria propõe uma mudança de paradigma, na qual afirma que a filosofia da consciência, que consiste na busca do entendimento individual sobre determinada circunstância, objeto e sociedade que cerca indivíduo não se sustenta. Para Habermas, a filosofia da linguagem ou da comunicação, que trata de atos comunicativos coletivos com vistas ao consenso, produz saber histórico-dialético contextualizado:

[...] não é a relação de um sujeito solitário com algo no mundo objetivo que pode ser representado e manipulado mas a relação intersubjetiva, que sujeitos que falam e atuam, assumem quando buscam o entendimento entre si, sobre algo. Ao fazer isto, os atores comunicativos movem-se por meio de uma linguagem natural, valendo-se de interpretações culturalmente transmitidas e referem-se a algo simultaneamente em um mundo objetivo, em seu mundo social comum e em seu próprio mundo subjetivo. (Habermas, 1997, p. 392).

Esta quebra de modelo é resultado de um afastamento do entendimento egocêntrico do mundo para uma abordagem mais humana e social, na qual os indivíduos através de atos comunicativos, chegam a entendimentos plurais do mundo que os cerca.

Deste modo, a ação comunicativa é coletiva e coordenada mediada pelo consenso plural advindo da comunicação:

[...] sempre que as ações dos agentes envolvidos são coordenadas, não através de cálculos egocêntricos de sucesso mas através de atos de alcançar o entendimento. $\mathrm{Na}$ ação comunicativa, os participantes não estão orientados primeiramente para o seu próprio sucesso individual, eles buscam seus objetivos individuais respeitando a condição de que podem harmonizar seus planos de ação sobre as bases de uma definição comum de situação. Assim, a negociação da definição de situação é um elemento essencial do complemento interpretativo requerido pela ação comunicativa. (Habermas, 1997, p. 285, 286).

A ação comunicativa proposta visa ações dos indivíduos nos atos comunicativos norteadas por seus objetivos individuais, porém com vistas ao entendimento harmônico plural através da argumentação e negociação.

Importante ressaltar que as contribuições de Habermas, como a Teoria da Ação Comunicativa, foram resultantes de diálogos com distintos autores, assim convém citar: 
[...] Habermas desenvolve sua teoria da ação comunicativa em um diálogo constante com autores de uma ampla gama de linhas teóricas. Assim, ele incorpora uma série de temas e contribuições que foram desenvolvidos, seja pelo funcionalismo, pela fenomenologia, pelo marxismo, ou pela própria teoria crítica da escola de Frankfurt, sua matriz original e mais importante. Desta forma, sua teoria assume naturalmente um caráter interparadigmálico, o que não significa, como veremos, um mero amálgama de várias linhas teóricas mas um processo extremamente rico de incorporação/superação. (Pinto, 1994, p.1)

Como parte de sua ampla teoria interparadigmática, Habermas construiu um conceito de racionalidade a partir dos atos comunicativos com base nas ideias de autores principais como: Weber, Durkheim, Lukács e Adorno, deste modo:

[...] Habermas acredita que, na estrutura da linguagem cotidiana, está embutida uma exigência de racionalidade pois, com a primeira frase proferida, o homem já manifestava uma pretensão de ser compreendido, uma busca de entendimento. (Aragão, 1992, p.82)

O conceito de racionalidade na comunicação tem suas bases na subjetividade do indivíduo, pois ao emitir uma mensagem, através da linguagem, este indivíduo possui intenções e pretensões de validade em busca do entendimento consensual.

O que denota a racionalidade de uma manifestação linguística são as pretensões do indivíduo passíveis a críticas, através da intersubjetividade:

Vou defender a tese de que há pelo menos quatro classes de pretensões de validez, que são co-originárias, e que essas quatro classes, a saber: compreensibilidade, verdade, correção e veracidade, constituem um complexo ao qual podemos chamar racionalidade (Habermas, 1994, p.121).

Deste modo, sendo as pretensões baseadas na empiria, sem bases em um referencial teórico evidente, o que transforma um argumento é "a sonoridade de suas razões" (Habermas, 1997, p. 24).

Com base nas pretensões de validade, (Habermas, 1997) estabelece três critérios universais de confrontação destas pretensões:

1 - Veracidade da afirmação que faz referência a um mundo objetivo compreendido como a soma dos fatos passível de verificação;

2- Correção normativa, trata-se de uma pretensão ligada a um mundo social dos indivíduos, fruto da totalidade intimamente reguladas nas conexões interpessoais;

3- Autenticidade e sinceridade que refere-se a um mundo subjetivo, baseado nas experiências do emissor, às quais, somente este tem acesso concedido. (Habermas, 1997).

Nestes critérios universais que fazem parte do conceito de racionalidade, Habermas estabelece diferenças entre os mundos objetivo, social e subjetivo. O primeiro critério pontua que as interpretações formuladas no mundo objetivo dependem de verificação, o segundo estabelece que as pretensões dos indivíduos no ato comunicativo, sofrem influência do seu meio social, o último critério postula que as pretensões são também resultantes das experiências subjetivas dos indivíduos.

Habermas (1990) define razão e racionalidade, estabelecendo diferenças: 
[...] a racionalidade em primeiro lugar a disposição por parte do sujeito falante e atuante de adquirir e utilizar um saber falível. Enquanto os conceitos básicos da filosofia da consciência impuserem que se compreenda o saber, exclusivamente como saber de algo no mundo objetivo, a racionalidade limitase ao modo como o sujeito isolado se orienta em função dos conteúdos das suas representações e dos seus enunciados.[...] Quando, pelo contrário, entendemos $\mathrm{o}$ saber como transmitido de forma comunicacional, a racionalidade limita-se à capacidade de participantes responsáveis em interações de se orientarem em relação a exigências de validade que assentam sobre o reconhecimento intersubjetivo. A razão comunicativa encontra os seus critérios no procedimento argumentativo da liquidação direta ou indireta de exigências de verdade proposicional, justeza normativa, veracidade subjetiva e coerência estética. (Habermas, 1990, p.291).

Sendo a racionalidade ligada às experiências subjetivas, a saberes falíveis, ao indivíduo isolado, a razão é compreendida como dialógica, concreta e comunicativa resultado de indagações, interpretações, compreensões, saberes transmitidos de maneira comunicacional, relações sociais de compartilhamento e conhecimento, construídos no mundo da vida.

Quanto à argumentação, Habermas propõe:

Chamo argumentação ao tipo de fala em que os participantes tematizam as pretensões de validez que se tornam duvidosas e tratam de aceitá-las ou recusá-las por meio de argumentos. Uma argumentação contém razões que estão conectadas de forma sistemática com as pretensões de validez da manifestação ou emissão problematizadas. A força de uma argumentação se mede num contexto dado pela pertinência das razões (Habermas, 1987, p. 37).

Para o referido autor o discurso argumentativo é formulado pelo indivíduo com base nas pretensões de validade que ao argumentar, torna o discurso aceito ou recusável pelos demais. A argumentação mede-se pela congruência da razão.

A racionalidade é demonstrada pelo indivíduo que faz parte de uma argumentação contestando de modo favorável ou não favorável àquelas razões apresentadas. As críticas advindas das argumentações tornam possíveis melhorias ao discurso. Para Habermas (1987) ao serem identificadas falhas no discurso, é possível um movimento de melhorias a fim de construir novos discursos argumentativos mediante os erros.

Habermas propõe em sua Teoria da Ação Comunicativa o afastamento de relações cognitivas entre indivíduos e objetos, em uma visão mais egocêntrica e solitária de mundo. Para ele, as relações cognitivas se dão por meio da comunicação em um movimento de indivíduo - outro - indivíduo para chegarem ao entendimento de suas pretensões.

Convém ressaltar que a linguagem é um diferencial na teoria de Habermas, sendo esta considerada como toda e qualquer forma de comunicação passível de modificar o comportamento dos indivíduos. Nesta concepção, a linguagem é o elo de interação entre os indivíduos, de modo a assegurar a democracia das decisões consensuais através de argumentações.

\section{A linguagem nos espaços educativos: uma reflexão sobre o uso dos diferentes gêneros textuais}

A Teoria da Ação Comunicativa (1997) de Habermas foi crucial para a compreensão da linguagem como fator social preponderante para comunicação, capacitação e emancipação 
dos indivíduos. Propõe conceitos de racionalidade inerente ao indivíduo e de razão ligada à comunicação em relações sociais. Tal teoria, propicia reflexões em todos os âmbitos sociais, mas principalmente nos espaços educativos, por serem espaços destinados ao desenvolvimento e aprimoramento da comunicação, do pensamento crítico, reflexivo e do conhecimento.

Nos espaços educativos a linguagem também é compreendida como a capacidade de comunicar-se através do uso, da língua como código, sendo a palavra oral ou escrita um meio de expressão e de comunicação entre os indivíduos de maneira interativa:

[...] a língua é tida como uma forma de ação social e histórica que, ao dizer, também constitui a realidade, sem contudo cair num subjetivismo ou idealismo ingênuo. [...] Assim, toda a postura teórica aqui desenvolvida insere-se nos quadros da hipótese sócio-interativa da língua. É neste contexto que os gêneros textuais se constituem como ações sócio discursivas para agir sobre o mundo e dizer o mundo, constituindo-o de algum modo. (Marcuschi, 2005, p. 22)

Para Marcuschi (2008) o gênero textual está entre o discurso e o texto. O referido autor postula que o discurso é entendido como a ação linguística ligada a uma prática social em um contexto histórico, já o texto é o fenômeno empírico linguístico com elementos próprios. Compreende o gênero textual como ação textual e discursiva em um momento histórico que se produz e circula socialmente.

O discurso é compreendido como prática discursiva em distintos tipos de discurso no plano da enunciação, estes elementos convergem com o gênero que se relaciona em um movimento de idas e retornos para o texto, que é entendido como o objeto empírico.

Para Coutinho (2004) o discurso é:

Uma enunciação em que entram os participantes e a situação sócio-histórica da enunciação. Além disso, entram aspectos pragmáticos, tipológicos, processos de esquematização e elementos relativos ao gênero. $\mathrm{O}$ que perpassa todas as posições teóricas em relação ao discurso é o fato de se tratar de uso interativo da língua. (Coutinho, 2004, p. 33).

Sendo o discurso uma situação enunciativa que ocorre entre indivíduos em um contexto sócio-histórico, o mesmo autor postula que o texto se trata:

De uma configuração, ou seja, de uma esquematização que conduz a uma figura ou uma figuração. Não se trata de uma ordenação de enunciados em sequência e sim de uma configuração global que pode ter até mesmo um só enunciado ou mesmo um romance inteiro. (Coutinho, 2004, p. 34).

O texto é uma ordenação global de enunciados, sendo o objeto empírico do discurso. Diante disso, necessário definir os gêneros textuais. Cabe citar Coutinho (2004) que destaca dois elementos dos gêneros textuais:

(a) gestão enunciativa (escolha dos planos de enunciação, modos discursivos e tipos textuais); (b) composicionalidade (identificação de unidades ou subunidades textuais que dizem respeito à sequenciação e ao encadeamento e linearização textual) [...] o gênero prefigura o texto e o gênero define o que o texto empírico faz a figura do texto. (Coutinho, 2004, p. 37). 
Os gêneros textuais são geridos pela enunciação e elementos composicionais em uma sequenciação textual.

Deste modo, os gêneros textuais se comportam como a intenção comunicativa do texto oral ou escrito em relação ao outro indivíduo. Para Marcuschi (2008), os estudos sobre os gêneros textuais são antigos e se iniciaram com Platão na Grécia Antiga e com Aristóteles que criou uma teoria sobre o discurso, apontando a existência dos seus elementos constituintes: falante e ouvinte.

Assim, os gêneros textuais fazem parte do discurso, pois para que algo seja considerado um texto, este deve possuir significação e transportar uma mensagem ao interlocutor. Marcuschi (2008, p. 78) considera que: “[...] sabemos que os textos são desenhados para interlocutores definidos e para situações nas quais supomos que os textos devem estar inseridos", isto é, cada gênero textual tem seu lugar em determinada situação comunicativa para transmitir a mensagem àquele(s) interlocutor(es).

Marcuschi (2008) estabelece que:

Gênero textual se refere aos textos materializados em situações comunicativas recorrentes. Os gêneros textuais são os textos que encontramos em nossa vida diária e que apresentam padrões sociocomunicativos característicos definidos por composições funcionais, objetivos enunciativos e estilos concretamente realizados na integração de forças históricas sociais institucionais e técnicas. [...] Alguns exemplos de gêneros textuais seriam: telefonema, sermão, carta comercial, carta pessoal, romance, bilhete, reportagem, aula expositiva, reunião de condomínio, notícia jornalística, horóscopo, receita culinária, bula de remédio, lista de compras, cardápio de restaurante, instruções de uso, inquérito policial, resenha, edital de concurso, piada, conversação espontânea, conferência, carta eletrônica, bate-papo por computador, aulas virtuais e assim por diante. Como tal, os gêneros são formas textuais escritas ou orais bastante estáveis, histórica e socialmente situadas. (Marcuschi, 2008, p. 155)

Assim, determina que os gêneros textuais são textos orais ou escritos, relativamente estáveis, em situações comunicativas diárias que possuem composições funcionais e objetivos enunciativos situados historicamente.

Para Marcuschi (2008), os gêneros textuais "são entidades empíricas em situações comunicativas e se expressam em designações diversas, constituindo em princípio listagens abertas." (Marcuschi, 2008, p. 155). Deste modo, os gêneros são a língua em uso oral ou escrito, há uma lista infinita de gêneros textuais distintos:

Os gêneros textuais são dinâmicos, de complexidade variável e não sabemos ao certo se é possível conta-los todos, pois como são sócio-históricos e variáveis, não há como fazer uma lista fechada, o que dificulta ainda mais a sua classificação. Por isso é muito difícil fazer uma classificação de gêneros. Aliás, quanto a isso, hoje é mais uma preocupação dos estudiosos fazer tipologias. A tendência hoje é explicar como eles se constituem e circulam socialmente. (Marcuschi, 2008, p. 159).

Sobre os gêneros textuais, Marcuschi (2008) ainda postula:

Na realidade, o estudo dos gêneros textuais é uma fértil área interdisciplinar, com especial atenção para o funcionamento da língua e para as atividades culturais e sociais. Desde que não concebamos os gêneros como modelos 
estanques, nem como estruturas rígidas, mas como formas culturais e cognitivas de ação social corporificadas de modo particular na linguagem, temos de ver os gêneros como entidades dinâmicas. (Marcuschi, 2008, p. 156).

O gênero textual é o uso da língua em atividades sociais e culturais, seus modelos não são isolados, nem sua estrutura é imutável, mas dinâmico e em constante transformação em conjunto com o funcionamento da língua.

Nesse sentido, em situação comunicativa e cotidiana, compreende-se:

Uma noção cotidiana usada pelos falantes que se apoiam em características gerais e situações rotineiras para identificá-lo. Tudo indica que existe um saber social comum pelo qual os falantes se orientam em suas decisões acerca do gênero de texto que estão produzindo ou que devem produzir em cada contexto comunicativo. Esses gêneros não surgem naturalmente, mas se constroem na interação comunicativa e são fenômenos sociointerativos. (Marcuschi, 2008, p. 187).

Os gêneros são produzidos em situações comunicativas e adequados a estas situações. Os gêneros não aparecem por acaso, são construídos na interação comunicativa e são resultados desta interação.

Cada gênero textual possui uma composição, um objetivo e pode conter um ou mais tipos textuais. Segundo Marcuschi (2008), o tipo textual "caracteriza-se muito mais como sequências linguísticas (sequências retóricas) do que como textos materializados; a rigor, são modos textuais." (Marcuschi, 2008, p. 154). Os tipos textuais são restritos e conhecidos como: argumentação, descrição, exposição, injunção e narração.

Sendo assim, é importante ressaltar que os gêneros textuais e tipos textuais variados devem se fazer presentes em todas as disciplinas e níveis de ensino nos âmbitos escolares para desenvolvimento pleno da oralidade, leitura e escrita:

O falante deve saber flexionar os verbos e usar os tempos e os modos verbais para obter os efeitos desejados; deve saber usar os artigos e os pronomes para não confundir seu ouvinte [...]. Mas ele não precisa justificar com algum argumento porque faz isso ou aquilo nessas escolhas. $\mathrm{O}$ falante de uma língua deve fazer-se entender e não explicar o que está fazendo com a língua. (Marcuschi, 2008, p. 57)

As instituições de ensino devem garantir ao estudante plena participação na sociedade contemporânea, assegurando o pleno domínio da língua oral e escrita para participação na sociedade e exercício da cidadania. Para Marcuschi (2008) "[...] o ensino é sempre o ensino de uma visão de objeto e de uma relação com ele [...] objeto: a língua[...] e os fenômenos: o texto, os gêneros e a compreensão. (Marcuschi, 2008, p. 50).

Nessa visão, as Diretrizes Curriculares $(2008)^{3}$ preveem o estudo dos gêneros textuais em sala de aula: "o gênero [...] é uma prática social e deve orientar a ação pedagógica com a

\footnotetext{
${ }^{3}$ As Diretrizes Curriculares Estaduais de Língua Portuguesa do Estado do Paraná - Brasil (2008), foram elaboradas por profissionais da educação e distribuídas pelo Governo do Estado, resultantes da investigação nas escolas e discussão coletiva ao longo de quatro anos. Estas Diretrizes, discutem a organização do currículo, com base nos conteúdos e conceitos de conhecimento, interdisciplinaridade e avaliação, com fundamentos teóricometodológicos e conteúdos para o fazer docente, além de contextualizar os âmbitos sociais, econômicos, políticos e seus efeitos no Ensino Fundamental e Médio.
} 
língua, privilegiando o contato real do estudante com a multiplicidade de textos produzidos e que circulam socialmente." (Paraná, 2008, p. 21).

Sobre o entendimento dos gêneros textuais: "Os gêneros variam assim como a língua - a qual é viva, e não estanque. As manifestações comunicativas mediante a língua não acontecem com elementos linguísticos isolados, elas se dão [...] como discurso." (Paraná, 2008, p. 52).

Ao abordar cada gênero textual o docente deve considerar: "o tema [...], a forma composicional e o estilo (marcas linguísticas e enunciativas) [...] o professor propiciará ao aluno a análise crítica do conteúdo do texto [....], é preciso considerar o interlocutor do texto, a situação de produção, a finalidade, o gênero ao qual pertence [...].” (Paraná, 2008, p. 64).

O uso dos gêneros textuais em sala proporciona o desenvolvimento das habilidades leitora e escrita, pois estas, são vistas como formas interativas de aplicação da língua dentro e fora do espaço escolar. Assim, "o texto é visto como lugar onde os participantes da interação dialógica se constroem e são construídos.” (Paraná, 2008, p. 21).

Nesta relação dialógica, proposta pelos documentos oficiais (2008), entre locutor e interlocutor no meio social, na construção de enunciados, os participantes desta interação, proposta por Habermas (1997) por meio da linguagem, atuam em igualdade. O indivíduo que emite a mensagem, a fórmula de modo compreensível, enquanto o receptor compreende o enunciado de modo interno e externo, relacionando- a seus pensamentos, conhecimentos e produzindo um novo enunciado oral ou escrito, segundo Marcuschi (2008). Assim dialogam com os pressupostos dos documentos oficiais do estado do Paraná (2008), a teoria da ação comunicativa de Habermas (1997) e a teoria de Marcuschi (2008).

Comungando das mesmas ideias, Geraldi (1991) sugere que o professor e o linguista devem ser uma só pessoa, pois, argumenta que não é necessário arquitetar ligações entre a linguística e o ensino, isto deve ser natural, sendo entendido como o ensino da leitura, interpretação e compreensão, papel de todos os professores de diferentes disciplinas mediadas pelos gêneros textuais. Assim sugere: “[...] acontece, porém, que, na escola, na compreensão e na produção dos textos e na análise linguística, a linguagem não se dá como objeto epistemológico. Dá-se por inteiro, em sua dimensão política, histórica, social e contextual." (Geraldi, 1991, p.45).

O espaço escolar mediado pela linguagem oral e escrita, entendida como fator interativo, social, político, histórico e cultural, deve estar preparado para desenvolver nos estudantes, através do ensino e prática dos gêneros textuais em suas múltiplas formas; a boa comunicação, o desenvolvimento do pensamento crítico e o conhecimento científico para emancipação dos indivíduos nos meios sociais.

\section{Considerações Finais}

Segundo Habermas (1997) a linguagem propicia a organização do mundo subjetivo e social. Em uma relação dialógica, os indivíduos interagem igualmente expondo sua subjetividade imbuída de conhecimentos adquiridos nos meios sociais. Nesta relação, constroem-se e são construídos.

Ao visualizar a linguagem a partir do processo interacional é também possível pensar o processo educacional, à medida que a produção da linguagem e dos indivíduos, neste espaço, ocorre em um processo interlocutivo, em constante desconstrução e construção cognitiva, subjetiva e social por meio das interações com os demais indivíduos.

Conceitua a racionalidade na comunicação e afirma que está calcada na subjetividade do indivíduo. Ao emitir uma mensagem, o indivíduo possui pretensões de validade e intenções com a finalidade de expor sua mensagem com objetivo do entendimento consensual. As 
pretensões do emissor denotam a racionalidade em uma manifestação linguística, suscetíveis a críticas advindas da intersubjetividade.

Afirma que a razão é concreta, dialógica e comunicativa, sendo consequência de reflexões, e interpretações das informações e saberes compartilhados na situação comunicativa, construídos no mundo da vida.

Ao pensar a linguagem em uma coletividade de ações humanas, onde há o intento de interagir de acordo com intenções e motivações, surge o texto como produto, os gêneros textuais.

Marcuschi (2008) aborda a teoria dos gêneros textuais e tipos textuais e afirma que os gêneros textuais são textos escritos ou orais, moderadamente estáveis, em situações de comunicação, que apresentam objetivos enunciativos e composições funcionais situadas historicamente.

Defende que o gênero textual é a prática social da língua em uso nas atividades sociais, com estrutura mutável e modelos dinâmicos e em constante transformação em conjunto com o funcionamento da língua.

Postula que o trabalho com os gêneros textuais em sala de aula, é uma oportunidade de estudar a língua em seus distintos usos ou práticas sociais distintas. Defende que o entendimento do funcionamento dos gêneros é crucial para exercícios de produção e compreensão de textos.

Em consonância com Habermas (1997) e Marcuschi (2008) os documentos oficiais do Estado do Paraná - Brasil (2008) preveem que o uso dos gêneros textuais em sala de aula propicia o desenvolvimento das habilidades escrita e leitora como formas de interação e aplicação da língua para conhecimento e uso também fora dos espaços escolares. Sendo a escola um espaço social, os gêneros compartilhados são construídos e são construídos em uma interação dialógica e social.

Ao trabalhar com a linguagem em suas múltiplas formas de uso, os conhecidos gêneros textuais, os espaços educativos preparam o estudante na elaboração dos seus próprios discursos, para que obtenha maior eficácia em sua atuação social.

Tendo em vista este trabalho com a linguagem, a escola deve proporcionar leituras e reflexões dos diferentes gêneros textuais em diversos contextos de uso para que haja interação entre leitor, leitores e objeto lido em constante desconstrução e construção cognitiva.

O presente artigo apresentou algumas reflexões pertinentes à área da Educação com vistas para a linguagem e os gêneros textuais, para isto, utilizou-se a Teoria da Ação Comunicativa de Habermas (1997), a linguagem nos espaços educativos por meio dos gêneros textuais propostos pelos Diretrizes Curriculares do Estado do Paraná (2008) e a teoria dos gêneros textuais de Marcuschi (2008). Acredita-se que estas reflexões podem servir de norte para continuidade e aprofundamento deste estudo, bem como, suscitar interesse para novas contribuições ou comparações relacionadas.

\section{Referências Bibliográficas}

ARAGÃO, L.M. de C. (1992). Razão Comunicativa e teoria social crítica em Jürgen Habermas. Rio de Janeiro. Tempo Brasileiro.

COUTINHO, A. (2004). Schematisation (discursive) et disposition (textuelle). In: ADAM, J. M.; GRIZE, J. B.; BOUACHA, M. A. (Org.). Texte et discours: categories pour l'analyse. Dijon: Editions Universitaires de Dijon. 
GERALDI, J. W. (1991). O texto na sala de aula. São Paulo: Editora Martins Fontes.

HABERMAS, J. (1987). Teoría de la acción comunicativa I: Racionalidad de la acción y racionalización social. Tradução de Manuel Jiménez Redondo. Madrid: Taurus.

HABERMAS, J. (1989). Consciência moral e agir comunicativo. São Paulo: Brasiliense.

HABERMAS, J. (1990). O discurso filosófico da modernidade. Lisboa: Dom Quixote.

HABERMAS, J. (1994). Teorías de la verdad. In: Teoría de la acción comunicativa: complementos y estudios previos. 2.ed. Tradução de Manuel Jiménez Redondo. Madrid: Cátedra.

HABERMAS, J. (1997). Teoría de la acción comunicativa: complementos y estudios previos. Madrid: Cátedra.

MARCUSCHI. L.A. (2005). Gêneros textuais: definição e funcionalidade. In: DIONÍSIO, A. P.; MACHADO, A. R.; BEZERRA, M. A. Gêneros Textuais e Ensino. $4^{\text {a }}$ Ed. Rio de Janeiro: Lucerna.

MARCUSCHI. L.A. (2008). Produção textual, análise de gêneros e compreensão. São Paulo: Parábola Editorial.

PARANÁ. (2006). Secretaria de Estado de Educação. Superintendência de Educação. Diretrizes Curriculares de Língua Portuguesa para a Educação Básica do Estado do Paraná. Curitiba: SEED.

PINTO, J. M. R. (1994). Administração e Liberdade: Um estudo do Conselho de Escola à luz da teoria da ação comunicativa de Jürgen Habermas. (Tese de doutorado). Faculdade de Educação/UNICAMP, Campinas. 